\title{
Comunidades de vida no Espírito Santo juventude e religião
}

\author{
Cecilia Loreto Mariz
}

A importância da juventude nas comunidades de vida no Espírito Santo

Quem estuda a Renovação Carismática Católica (RCC) no Brasil tem se surpreendido com o surgimento e o crescimento das chamadas "comunidades de aliança e vida no Espírito Santo". No Brasil, esse é um fenômeno recente, registrado pelos pesquisadores apenas a partir do final da década de 1990 e nos anos de 20001. Criadas por participantes de grupos de oração carismática, essas comunidades são um fenômeno internacional, já observado por Thomas Csordas (1997) nos Estados Unidos e por Martine Cohen $(1990,1997)$ na França. Leigos decidem se reunir para se dedicar ao louvor, à adoração ao Santíssimo, à evangelização, à cura espiritual e às mais diversas obras sociais. No léxico das comunidades, essas atividades são chamadas de "carismas".

Entre seus membros, existem aqueles que procuram um tipo especial de consagração e passam a compartilhar as finanças e o cotidiano com outros, dividindo o mesmo teto e as despesas domésticas: formam a chamada "comunidade de vida". Os demais, que continuam a morar com seus familiares e a manter sua autonomia econômica, constituem a "comunidade de aliança”. Alguns entrevistados afirmaram que ambas as comunidades são parte de um todo e não há hierarquia espiritual que defina a superioridade da opção de participar da "comunidade de vida"; contudo,
1. Não encontramos registros de pesquisadores sobre as comunidades de vida até o final da década de 1990. Em seu livro, Machado (1996) refere-se às comunidades Emanuel e Bom Pastor, no Rio de Janeiro, que eram apenas "de aliança”, mas nada comenta sobre comunidades de vida. Referências a estas aparecem em Carranza (2000), que aponta sua existência em Campinas, e em Miranda (1999), que descreve especialmente a comunidade Shalom de Fortaleza. Os trabalhos de Oliveira (2003, 2004) são dedicados à comunidade Canção Nova. 
2. Projeto apoiado pelo CNPq desde 2003 e desenvolvido com equipe de bolsistas de Iniciação Científica (em 2004 e 2005, Paulo LeiteLopes, Débora Minuzzi e Walace Ferreira, e, em 2003, Rosiane Silva, Eduardo Nazareth, Jocilene Serqueira e Jana Lessa) e de Apoio Técnico (em 2004-2005, Rosiane Silva).

3. Os líderes da Toca de Assis entrevistados enfatizam o projeto de se tornar uma congregação religiosa, e não se identificam totalmente com o conceito de comunidade de aliança e vida carismática. No entanto, as trajetórias de seu fundador e membros, e a dinâmica de crescimento e funcionamento, assemelham-se muito com as outras comunidades analisadas. Além disso, há uma forte ligação entre a Toca de Assis e a Canção Nova, como mostra Oliveira (2003).

4. Segundo um entrevistado, essa comunidade, cuja casa principal se localiza em Austin, na Baixada Fluminense, RJ, surgiu a partir de experiências da RCC e seu objetivo inicial era "simplesmente reunir os jovens numa tarde de louvor". os membros "de aliança" revelam admiração especial pelos que optaram pela vida consagrada. A manutenção daqueles que estão na "comunidade de vida" depende em geral dos membros da comunidade de aliança: são eles que os apóiam materialmente.

Como seguem uma dinâmica laica e não institucional, essas comunidades não têm sido sistematicamente registradas, nem pelos setores administrativos das paróquias e dioceses, nem pelo próprio movimento de Renovação Carismática. Dessa forma, não é fácil estimar quantas comunidades desse tipo existem no Brasil. Em pesquisa preliminar ${ }^{2}$ sobre o tema foram obtidos dados sobre comunidades no Rio de Janeiro por intermédio de relatos dos membros da RCC: um dos entrevistados diz ter ouvido falar de uma comunidade de vida, outro fornece um endereço e, a partir dessas informaçōes, procuramos fazer contato e visitas; nas comunidades visitadas, descobrimos mais informaçôes sobre outras.

Há comunidades de vida muito conhecidas e citadas por um grande número de entrevistados, dentre as quais se destacam a Canção Nova, a Shalom e a Toca de Assis ${ }^{3}$. Dispondo de homepages e de diversas publicaçôes, essas comunidades possuem casas em vários estados do país e também no exterior, no caso das duas primeiras.

Uma característica que chamou a atenção nessas três comunidades de vida, mas também em outras sobre as quais existem dados levantados, foi a juventude de seus membros. Tendo sido criadas para jovens ou por jovens, a importância deles nessas comunidades é sempre ressaltada, seja nos textos divulgados pela internet, seja nos depoimentos dos entrevistados. A juventude também parece ter papel importante nas demais comunidades estudadas no Rio de Janeiro, como a Novo Maná ${ }^{4}$ a Eis o Cordeiro e até mesmo a Bom Pastor, uma comunidade basicamente de alianças.

O papel da juventude na origem da Shalom é bem destacado em um relato do site dessa comunidade (www.shalomrj.com.br):

\footnotetext{
Nascida no meio dos jovens, a comunidade surgiu de um ardente desejo de evangelizar os jovens mais afastados de Deus. Transformamos uma lanchonete em um meio de atração dos jovens a Deus. Com eles vieram as famílias, as crianças e todo um povo se formou ao redor da obra.
}

Com efeito, a Shalom foi criada por um jovem, como ressalta um membro da sede de Botafogo, no Rio de Janeiro: “[...] a comunidade nasceu há 22 anos, em 1982, lá em Fortaleza. O nome do fundador é Moysés do 
Rego, um jovem que foi inspirado por Deus na época e já participava de grupo de oração e tudo, e foi inspirado por Deus".

Os fundadores da Canção Nova e da Toca de Assis, respectivamente um padre e um seminarista, declaram que foram os jovens que os motivaram a criar a comunidade de vida.

Ao falar sobre sua inspiração para criar a comunidade de vida Canção Nova e para se dedicar ao carisma de evangelizar pela mídia, o padre Jonas Abib refere-se diretamente ao seu trabalho com os jovens. Em suas declarações divulgadas no site, deixa clara a importância da juventude:

[...] fiz o desafio e uma grande quantidade de jovens aceitou. Isto significava que realmente já estavam experimentando a necessidade de se entregar àquele Cristo que começavam a descobrir. [...] Não sabia em que aventura estava me colocando. Pensei que iria ficar só naquele catecumenato... Já aconteceu tudo isso! (Em www.cancaonova.com/ cnova/pejonas/comunidade 02.php, consultado em 3 de setembro de 2005).

O primeiro núcleo de vida iniciou-se com o padre Jonas e doze jovens. Segundo narra Brenda Carranza (2000), esse padre já tinha muita experiência na pastoral de jovens e por alguns anos vinha liderando o movimento católico "Encontros de Jovens" em Lorena.

Também a Toca de Assis tem a marca da juventude em sua origem. No site oficial da comunidade, há várias informações sobre seu fundador. Nascido em 1962, o padre Roberto Lettieri teria se convertido em 1983, aos 21 anos, quando participava de um desses "Encontros de Jovens". O primeiro núcleo da Toca foi formado, em 1994, por três jovens, sob a liderança do padre Roberto, que aos 31 anos de idade era ainda seminarista. $\mathrm{O}$ site informa que: "Quando ordenado sacerdote, em 8 de dezembro de 1996, esta obra, espelhada nos exemplos de pobreza, obediência, castidade e gratuidade do 'Poverello de Assis', já contava com a ajuda de oitenta jovens" (www.tocadeassis.org.br/fundador.html, consultado em 3 de setembro de 2005).

Embora em todas as comunidades se declare que não são aceitos menores de 18 anos, idade mínima para se consagrar, são comuns os comentários sobre a existência em alguma casa da comunidade de uma consagrada com 16 ou 17 anos, que no entanto são consideradas casos excepcionais, de pessoas "muito maduras em termos espirituais".

Das três comunidades citadas, que têm abrangência nacional, a Toca de Assis destaca-se pela pouca idade de seus membros. Pelas declaraçôes
5. Segundo a fundadora da Bom Pastor, a comunidade "era um grupo de oração. Começamos com o próprio jovem. Meu marido e eu e mais quatro jovens, minha filha e minha sobrinha e mais dois jovens, e daí então a casa ficava com a porta encostada em dia de oração e as pessoas iam entrando". Essa comunidade tem orgulho de dizer que lá se descobriu a vocação de uma freira e de um padre (o padre Zeca, muito conhecido no Rio como animador do evento juvenil "Deus é Dez").

6. Como no caso da comunidade Eis o Cordeiro, em Niterói, que possui apenas uma casa, e também da comunidade Toca de Assis. 
7. A entrevistada, na casa das mulheres da Toca, em Santa Teresa, Rio de Janerio, explicou: "O de menor tá mais difícil de entrar, porque antes entrava com treze anos, catorze, mas agora tá precisando, pela lei, de estudar".

8. Ver entrevista citada em artigo anterior sobre o tema (Mariz, 2005).

9. Dados sobre o entusiasmo dos jovens da RCC aparecem em Carranza (2000) e Oliveira (2003). Fervor similar foi observado por Rozicléa E. do Nascimento no templo da Igreja Universal na Favela da Maré, Rio de Janeiro, durante pesquisa promovida pelo Ceris (Centro de Estatística Religiosa e Investigação Social) em 1994, cujos resultados foram publicados em Mariz (2001). dos entrevistados, essa idade poderia ser ainda menor, se fosse legalmente permitido ingressar com menos de 18 anos. $\mathrm{Na}$ época da coleta de dados para nossa pesquisa, observamos que em duas casas da Toca a maior parte dos membros tinha menos de 25 anos e a idade de ingresso era ainda menor ${ }^{7}$. Ao abandonar o estudo e a profissionalização, ou o projeto de formação de uma família pelo casamento, esses jovens passam a viver apenas de doações, e se tornam aquilo que Weber (1991) chamava de um "virtuose religioso". Sem dúvida, há problemas práticos na idade madura que tornam a opção por comunidades de vida menos viável. Os membros das comunidades de aliança, mais velhos, muitos com mais de 40 anos, deixam claro em seus depoimentos que não puderam, como os mais jovens, optar por viver integralmente para a "obra"; comentam que essa opção é possível apenas na juventude, quando ainda não foram assumidos compromissos anteriores ${ }^{8}$.

Essa retórica sobre a importância da juventude e principalmente a pouca idade de ingresso nessas comunidades levaram-nos a refletir sobre o papel dos jovens não apenas nesse tipo de experiência, mas nos movimentos religiosos em geral, em especial nos de cunho reavivado. Vários são os relatos de pesquisas que descrevem o fervor de jovens em eventos da Renovação Carismática e de igrejas pentecostais'. Sílvia Fernandes (2004), em sua pesquisa com seminaristas e noviças, encontrou jovens que "descobriram sua vocação" participando da RCC. Em seu estudo sobre a Igreja Universal do Reino de Deus no Rio de Janeiro, Bárbara Serrano (2003) observa um grupo de jovens missionários que seriam verdadeiros "virtuoses religiosos" no sentido weberiano. Essa atração dos jovens por um tipo de opção religiosa mais radical aparece ainda no trabalho de Patrícia Birman (2000), em que analisa atitudes e discursos de pais franceses cujos filhos ingressaram em grupos tidos como "seitas". Analisar uma possível relação entre juventude, subjetividade juvenil e virtuosismo religioso na sociedade contemporânea é uma das questôes deste artigo.

\section{Juventude e virtuosismo religioso: retóricas e dados}

Se, por um lado, constatamos uma atração dos jovens pelas comunidades, por outro podemos também perceber uma retórica sobre a maior capacidade da juventude de "doar-se". É comum, no discurso das pastorais católicas que procuram mobilizar a juventude, haver referências à "generosidade natural do jovem". No papado de João Paulo II ficou bem clara a 
ênfase dada às pastorais juvenis, especialmente com a organização e a presença do próprio pontífice nas Jornadas Internacionais da Juventude (cf. Carranza, 2000).

Esse tipo de retórica em torno do potencial de bondade juvenil teria surgido no Ocidente, segundo Philippe Ariès (1981), a partir do final do século XIX e início do XX, quando se idealiza a espontaneidade e a pureza dessa etapa da vida. A figura do jovem é construída como a de um herói belo e corajoso. O conceito de juventude constitui-se, dessa forma, ancorado em uma visão romântica. Ariès comenta: "A juventude, que então era a adolescência, iria tornar-se um tema literário, e uma preocupação dos moralistas e políticos. [...] A juventude apareceu como depositária de valores novos, capazes de reavivar a sociedade velha e esclerosada" (Idem, p. 14).

A subjetividade juvenil é concebida como oposição aos padrōes burocráticos e mercantis característicos da era moderna. Guiados pela lógica da natureza, do sentimento e da dádiva desinteressada, os jovens caracterizarse-iam por uma índole e uma subjetividade próprias, que os aproximariam de valores comunitários presentes nas diferentes religiōes, mas também de ideologias políticas que se opõem à sociedade capitalista moderna. Nesse sentido, o jovem é concebido como alguém mais propenso a atitudes heróicas e a virtuosismos religiosos, que busca a santidade e também a revolução, e que morreria por uma causa. No entanto, seria visto também, por isso, como menos racional e menos crítico. $\mathrm{O}$ espírito crítico (não no sentido de oposição, mas de análise racional) e o conhecimento prático seriam virtudes da maturidade.

A partir dessa perspectiva, tornam-se compreensíveis tanto os investimentos das religiōes na juventude como, do lado oposto, o cuidado dos pais e responsáveis em proteger os jovens de grupos religiosos e ideológicos que possam "aproveitar-se" de sua generosidade e ingenuidade. Esse cuidado aparece nos discursos da mídia francesa e dos pais vinculados à associação de familiares de vítimas de seitas, analisados por Birman (2000). A atração da juventude pelas chamadas "seitas" era entendida como resultado de seu baixo espírito crítico. Em conseqüência, como comenta a autora, a nova lei que concede a maioridade aos 18 anos de idade na França foi considerada negativa, por dar autonomia a pessoas imaturas.

No entanto, a relação entre juventude e virtuosismo religioso não pertence à retórica contracultural, em que a juventude é relacionada à "liberdade individual" e ao "hedonismo", que se expressa por exemplo no lema 
“é proibido proibir". Nesse discurso, a rebeldia, a luta pela liberdade e a rejeição às normas são a marca do espírito juvenil.

Em que medida essas distintas retóricas possuem correspondências empíricas? A análise de alguns dados pode ajudar a responder essa questão. No censo de 2000, no Brasil, segundo Novaes (2004, p. 322), os jovens (indivíduos pertencentes à faixa etária dos 15 aos 25 anos) estão entre os relativamente mais secularizados, uma constatação confirmada por um conjunto de pesquisas sobre a religião entre os estudantes universitários. $\mathrm{O}$ percentual de universitários que se declaram sem religião tende a ser sempre maior do que o encontrado na população mais ampla (cf. Steil, Alves e Herrera, 2001; Camurça, 2001; Cardoso, Perez e Oliveira, 2001, entre outros). Os dados revelam também que os jovens católicos são menos praticantes: a proporção dos que se dizem católicos praticantes é menor do que a encontrada em outras pesquisas entre a população mais ampla (cf., por exemplo, Fernandes, 2002).

A menor religiosidade dos jovens não necessariamente desmente dados e discursos sobre a atração pelo fervor e pelo virtuosismo religiosos. Uma interpretação possível seria a de que essas atitudes diferentes se referem a grupos sociais distintos: trata-se de distintas "juventudes", com culturas e subjetividades diferentes. No entanto, a interpretação que propomos aqui é a de que a própria experiência de juventude em nossa sociedade gera um tipo de subjetividade capaz de levar o mesmo jovem, ou jovens com o mesmo perfil social ou a mesma vivência, a não ter religião alguma ou ter muita religião.

Estamos supondo, assim, que a juventude pode ser vista como uma variável independente. Dessa forma, seria possível não apenas usar a categoria jovem em referência a indivíduos de distintos estratos sociais no mundo contemporâneo, mas também assumir que, apesar de pertencerem a estratos distintos, compartilham algumas características sociais em comum por serem jovens. Assume-se, portanto, que ser jovem na sociedade contemporânea implica experiências específicas de vida às quais se atrela certa subjetividade mínima, que se caracterizaria por uma afinidade eletiva com os extremos ou "experiências radicais".

Uma análise aprofundada desse tipo de argumento exigiria discutir quais as definiçôes disponíveis de juventude, retomando a literatura existente sobre o que se entende por jovem, juventude, subculturas e subjetividades juvenis na sociedade contemporânea. Seria necessário destacar as especificidades contemporâneas dessas categorias e como elas foram historicamente construídas no Ocidente moderno. Fazer esse tipo de análise não é, no 
entanto, a proposta deste $\operatorname{artigo~}^{10}$, que pretende apenas levantar alguns pontos que podem ajudar a entender a relação entre juventude e virtuosismo religioso.

\section{Qual a definição de jovem na sociedade contemporânea?}

Como revelam numerosas etnografias sobre os mais diferentes povos não ocidentais, a maturação biológica dos indivíduos através de seu ciclo vital tem sido sempre uma marca social importante (cf., entre outros, EvansPritchard, 2002, pp. 257-258). Os antropólogos descrevem os mais distintos ritos de iniciação de entrada na idade adulta e a antropologia tem refletido comparativamente sobre a passagem da infância para a idade adulta no Ocidente e entre os diversos povos já estudados (cf. Mead, 1995, entre outros). A posição no ciclo vital, embora possa ser socialmente descrita, categorizada e/ou interpretada de formas distintas, baseia-se em alguns elementos da natureza biológica do ser humano. Tal como o gênero, a natureza impóe certo limite às distintas construçôes culturais possíveis e, dessa forma, sempre existem categorias que distinguem crianças de adultos, assim como sempre haverá as categorias homens e mulheres nas distintas sociedades no decorrer da história.

Tanto o status de gênero como o de idade (ou posição no ciclo de vida) são "status atribuídos", na medida em que dependem de características físicas definidas pela constituição biológica de cada um. No entanto, ao contrário do gênero e dos demais status atribuídos, a idade é, por definição, um status mutável, mas sua mudança também é atribuída. É inerente a esse status seu caráter passageiro: o indivíduo pode pertencer a uma coorte geracional ou grupo etário, como no caso dos nuer, descrito por EvansPritchard (2002), mas a etapa da vida inevitavelmente mudará.

Com efeito, em todas as sociedades, os status de "criança", "jovem", "adulto", "velho" são transitórios, como transitória é a vida. Desses, contudo, o de jovem parece ser o mais passageiro por ser concebido como situação intermediária em que o indivíduo deixa a infância e se torna adulto. Em muitos povos, segundo descrições de antropólogos, esse período liminar pode ser relativamente breve, mas muito intenso, marcado por ritos de iniciação cujas práticas por vezes chocam a sensibilidade ocidental contemporânea, pelo tipo de sofrimento físico que podem infligir aos indivíduos. O caráter radical e doloroso desses rituais e experiências reforça essa passagem como uma experiência coletiva ${ }^{11}$.
10. Há uma amplabibliografia, que não se pretende analisar aqui, orientada por Machado Pais e Bourdieu, que debate a conceituação de juventude e culturas juvenis na sociedade moderna contemporânea. Para uma análise desse debate e literatura, ver Sposito (2001).

11. Em certa medida, pode-se supor que o forte processo de individualização da sociedade moderna leva a que se exacerbe a rejeição ao sofrimento individual mesmo que seja por causas coletivas socialmente legítimas. 
Rituais de passagem para a vida adulta podem ser encontrados no mundo ocidental contemporâneo, mas tendem a ser cada vez menos intensos. Essa intensidade diminui ao mesmo tempo em que a experiência de liminaridade entre vida de criança e de adulto, ou seja, a juventude, se amplia.

Graças à flexibilização das normas sociais e mais recentemente ao desenvolvimento tecnológico, a sociedade moderna tem se destacado das sociedades que as precederam por oferecer aos indivíduos a possibilidade de negarem os status, como classe, profissão, religião, estado civil, renda, nacionalidade e até gênero, que lhes foram atribuídos por critérios alheios à sua vontade. Essas posiçóes, que em sociedades pré-modernas eram definidas pela tradição ou pelo coletivo, passam a ser, cada vez mais, interpretadas como escolhas individuais.

No entanto, quando a etapa da vida de um indivíduo - ou seja, sua idade - passa a ser calculada com exatidão em termos de anos vividos, o status de "jovem" ou "velho" a ela vinculado ganha uma natureza quase que objetiva, que parece se impor à vontade individual e até a decisões sociais. $\mathrm{Na}$ sociedade moderna, infância, juventude, maturidade e velhice passam a ser igualadas a um conjunto de anos vividos, ou definidas por ele. Portanto, o status referente ao ciclo biológico do indivíduo, ou idade, torna-se, ao contrário dos demais status acima citados, mais independente da escolha individual. Por outro lado, é na modernidade que o número de anos vividos ganha um papel importante como definidor da posição e da identidade social. Como mostra Ariès (1981, pp. 1-2), na modernidade a idade se torna parte fundamental da identidade individual. Esse autor comenta que as primeiras duas coisas que a criança aprende a dizer na sociedade contemporânea, para se identificar, são seu nome e sua idade, e ressalta que a preocupação com o registro da idade tem sido um fenômeno relativamente recente na história ocidental.

O que se argumenta aqui é que seria uma especificidade de nossa sociedade identificar os ciclos da vida a faixas etárias. Esse tipo de identificação é responsável pelo debate específico dessa sociedade sobre o número de anos que se vive para ser considerado jovem. Evidentemente, as diferentes propostas são arbitrárias: dos 14 aos 24 anos, dos 15 aos 25 anos, ou ainda as que a estendem até os 35 anos, ou que a subdividem em "adolescência" (até os 18 anos) e "juventude propriamente dita" (após os 18 anos). No entanto, na sociedade moderna a definição de juventude está também associada à possibilidade de se desempenhar papéis reservados aos adultos. Tanto que o adiamento do início da vida economicamente ativa e reprodutiva e o 
prolongamento do período de formação educativa, como já mostraram vários autores (cf. Campiche, 1997; Fulton, 2004, entre outros), têm ampliado a faixa etária definida como jovem, no Ocidente. Cada vez mais a juventude cobre uma faixa etária mais ampla. É significativo, contudo, que nessas mesmas sociedades a maioridade tenda a diminuir, o que significa que a expansão da categoria juventude não busca restringir a autonomia dos indivíduos que passam a fazer parte dessa categoria.

Nas sociedades tradicionais, a juventude é menos definida pela idade do que pelo fato de não haver o desempenho ainda dos papéis atribuídos aos adultos. Nessas sociedades, jovens são os que não se casaram ${ }^{12}$, não tiveram filhos ou ainda não estão no mercado de trabalho, por exemplo. Deixa-se de ser jovem não quando se alcança determinada idade, mas com o total ingresso no mundo adulto. Vive-se a experiência de ser jovem enquanto esse ingresso ainda não ocorreu totalmente e já houve o abandono dos papéis infantis. Vivendo nessa liminaridade, os jovens compartilham uma situação de fragilidade social, o que é verdade tanto em sociedades tradicionais como nas modernas.

Essa experiência de liminaridade seria comum a todos os jovens, independentemente de sua posição na estrutura social. Apesar de ser evidente a existência de várias juventudes na sociedade contemporânea, ou seja, vários tipos de jovens, correspondentes aos distintos estratos e grupos sociais, é possível falar no jovem em geral. Embora influenciada pela situação de classe, de etnia e de gênero, a categoria "juventude" teria relativa autonomia, como já foi argumentado.

A juventude, tal como a concebemos em nossa sociedade, é por definição um período de liminaridade e, portanto, socialmente instável e frágil. Esse estágio se torna cada vez mais prolongado e, mais do que em outros períodos da vida, parece fomentar a necessidade de sentimento de pertencimento e de comunhão.

Com efeito, essa necessidade não é exclusiva dos jovens. Bauman (2003) e vários autores antes dele - já destacou a proliferação de experiências e movimentos que tendem a suprir essa necessidade gerada também pelo próprio contexto global de modernidade avançada ${ }^{13}$. As "comunidades de vida no Espírito Santo" seriam, portanto, uma entre várias experiências que respondem a essa necessidade. Para entender o apelo que essas comunidades têm para os jovens propõe-se identificar similaridades entre as experiências nas "comunidades de vida no Espírito Santo" e outras experiências com conteúdos muito distintos mas que também atraem os jovens. A ênfase na
12. As categorias de senhora e senhorita, e a distinção, tradicionalmente usada no meio popular no Brasil, entre "moça" e "mulher", para identificar quem já teve iniciação sexual, apontam para o papel que, para o gênero feminino, esse tipo de iniciação desempenhava como marca de entrada no mundo adulto. Com a vida sexual deixava-se "de ser moça" e, se essa não ocorresse, a mulher poderia tornarse uma "moça velha".

13. Levando em conta a observação de Weber (1982a) sobre a dificuldade de dar sentido à morte, e conseqüentemente ao envelhecimento na sociedade moderna, pode-se pensar que essa é uma sociedade que estimula o prolongamento de um tipo de subjetividade juvenil que valoriza a mudança constante e carrega sempre um sonho de um futuro. A velhice e a morte seriam vistas como "fracassos" e “entregas” e não como fenômenos naturais. Jovem passa a ser um elogio e velhice uma acusação. 
14. Uma relação positiva entre juventude e espírito revolucionário tem sido identificada por alguns autores, como Zanetti (1999). experiência vivida e não no conteúdo ideológico dessas comunidades não significa negar a importância do papel desempenhado por esses conteúdos. Evidentemente, a interpretação das funções desempenhadas por determinadas experiências não é suficiente para entender todas as motivações de adesão, nem razões para criação dessas comunidades. Apesar de o crescimento dessas comunidades ocorrer por intermédio dos jovens, o fato de ser jovem não implica atração por esse tipo de comunidade. Como mostrado acima, os jovens são atraídos por várias outras experiências similares que possuem os mais diversos discursos. Por isso, outras interpretaçôes complementares são não apenas possíveis, mas necessárias.

A tentativa das "comunidades de vida" de relacionar juventude e "virtuosismo" ajuda a entender também a atração dos jovens por outras vivências e práticas extremas, como por exemplo as revolucionárias ${ }^{14}$. Busca-se, assim, identificar elementos nas "comunidades de vida" que estão presentes em outros grupos e experiências com conteúdos ideológicos bem distintos, mas que também atraem e apóiam jovens e outras pessoas que vivem em uma situação de liminaridade. Entre essas experiências destacamos o enfrentamento da dor, o sacrifício e o risco da morte, a ruptura com o passado e a efervescência coletiva.

\section{Experiência do sacrificio e do risco da morte}

Em todas as comunidades de vida existe o sacrifício da liberdade individual e do próprio "eu". Mas o que foi considerado sacrifício pelos entrevistados não foi o abrir mão da liberdade, mas outros tipos de provação, como o cansaço físico ou a dor da separação dos entes queridos quando a comunidade os envia para longe.

Relatos sobre esses tipos de sacrifício aparecem em várias comunidades, mas alguns dos mais fortes são os de membros da comunidade Toca de Assis. Como o principal "carisma” dessa comunidade é a adoração ao Santísissimo, os jovens revezam-se em turnos, ficando prostrados de joelhos duas horas ou mais por dia diante do sacrário. Além disso, para cumprir o segundo "carisma" com os pobres, cuidam de pessoas que vivem nas ruas e por vezes as trazem para suas casas de acolhimento. Ambos os carismas implicam um fardo físico e uma dose de sacrifício que os entrevistados sentem e descrevem.

Um dos entrevistados, um paulista de 25 anos que vivia na casa de Madureira, no Rio de Janeiro, conta sobre a atividade pastoral de rua: 
Então a gente sai pra rua, temos a Pastoral de Rua, então ficamos de manhã, de tarde e às vezes até à noite. Às vezes dormimos com eles até na rua, né, diante de uma realidade, de uma personalidade, a condição que o irmão se encontra [...] às vezes é muito flagelado pela sociedade, então a nossa presença muitas vezes incomoda porque foi muito maltratado [...].

Sobre o cotidiano da comunidade, o depoimento de uma jovem de 20 anos incompletos, entrevistada na casa da Toca de Assis de Santa Teresa, no Rio, é esclarecedor:

[...] um problema sério [...] é dormir [...] porque nossa vida é muito cansada, cansativa assim, [...] não existe assim um horário, até por causa da oração mesmo, aí quem adora de madrugada, então é uma hora a menos que dorme, né? Não tem um período assim de oito horas certinho [...] acorda cinco e meia aí tem os dias que não acorda tão [cedo], que nem domingo acorda seis e meia, não é uma regra [...] a gente faz o Sacramento todos os dias [...] então depende muito dos horários das igrejas $[\ldots]$.

Os toqueiros comentam que têm problemas nos joelhos devido às horas que permanecem em adoração.

Outra forma de sacrifício comum é o jejum, apontado como uma prática muito importante entre os membros da comunidade de vida Canção Nova. Um entrevistado descreve as regras dessa comunidade:

[...] uma regra de vida dentro da comunidade, todos os membros precisam participar da missa todos os dias - nós precisamos rezar o rosário todos os dias - não é nem o terço, é o rosário - e precisamos também fazer jejum quarta e sexta-feira. Precisamos também fazer o estudo da palavra. Tem que se virar pra fazer tudo isso durante o dia.

Embora importante no discurso cristão, o sacrifício não é de forma alguma uma prática nem um valor exclusivos dessa tradição religiosa. A importância do sacrifício individual nos rituais de fortalecimento de identidades coletivas é um tema bastante discutido nas ciências sociais. Os sacrifícios são também chamados de "mortificaçôes", por serem, de certa forma, experiências parciais da morte: é a morte dos impulsos do corpo e a experiência do início do processo de destruição do próprio corpo. Eles podem ser vistos também como uma forma de subjugar ou matar o "eu". 
Procurando analisar o significado da auto-renúncia religiosa, Peter Berger compara-a com a experiência masoquista e comenta:

[...] o masoquismo, pela sua auto-renúncia radical, proporciona o meio pelo qual o sofrimento e a própria morte do indivíduo podem ser radicalmente transcendidos, a ponto de o indivíduo não só achar suportáveis essas experiências, mas até as acolher cordialmente (1985, p. 68).

Dessa forma, esse tipo de experiência religiosa se aproximaria de experiências mais radicais que implicam violência e riscos à própria vida. Ao pôr em risco a própria vida, põe-se também a do outro. O confronto com a morte do "outro" e o risco da própria morte podem ser experiências bem próximas e complementares, especialmente quando ocorrem em contextos de luta violenta entre grupos, em uma guerra, por exemplo. Weber (1982b, p. 384) lembra que "a guerra cria [...] um sentimento de comunidade. A guerra promove, portanto, uma comunhão incondicionalmente dedicada e pronta ao sacrifício, entre os combatentes".

A partir desse tipo de interpretação da experiência do sacrifício e da guerra, pode-se propor uma explicação distinta da que Angelina Peralva (1996) apresenta sobre o que chamou "juvenização" da violência. A autora afirma:

A angústia da morte [...] parece ser um dos elementos igualmente presentes na base do engajamento do jovem em condutas violentas. No Brasil, além da marca deixada na experiência do surf ferroviário, a angústia da morte parece ser um elemento constitutivo de condiçôes subjetivas de engajamento do jovem favelado carioca no tráfico de drogas e na violência.

Ao contrário de Peralva, para quem os jovens estão procurando essa situação limite para supervalorizar sua individualidade, interpretamos esse comportamento como fruto de uma busca de fortalecimento de um "eu" coletivo, de uma busca de experiências coletivas mais fortes alimentadas pela turma ou gangue.

A aparente desvalorização da vida e o fato de experimentarem as situações de enfrentamento da morte como espetáculo não se explicariam por uma possível desvinculação em relação aos grupos, nem tampouco revelariam uma superindividualização. Parece mais provável que enfrentassem a morte para alimentar um sentimento grupal que, por sua força, pareceria 
protegê-los de toda a fragilidade mais ampla que vivenciavam. A realização da empreitada por parte de um jovem reforçaria o sentimento de poder dos demais. Aparentemente, um "surfista de trem" e um membro de uma comunidade de vida nada teriam em comum entre si, a não ser o fato de serem jovens. No entanto, além de se desviarem da sociedade mais ampla, estão experimentando a sensação de vitória e de reforço da solidariedade do grupo a que pertencem ao impor sofrimentos e riscos a si mesmos.

\section{Experiência de ruptura e de desvio}

Os jovens entrevistados comentam que, às vezes, são considerados loucos por sua opção de romper com os valores dominantes da sociedade mais ampla. A sensação de estar realizando uma ruptura fica evidente nas declaraçôes de vários entrevistados. Uma jovem cearense de 28 anos, que fazia parte da comunidade Shalom havia cinco anos, nos explica que "[...] na comunidade de vida, a pessoa é chamada a largar tudo para viver na comunidade, para viver onde ela for enviada, para viver a presença de Deus inteiramente, ela larga o seu trabalho, a sua família, o seu emprego para viver exclusivamente para a evangelização".

A decisão de sobreviver com doações, sem receber pelo trabalho que faz e sem controlar suas próprias despesas, não é compreendida pelos pais desses jovens. Em várias entrevistas, os jovens referem-se à reação de choque e oposição da família ao revelarem sua opção pela vida na comunidade. Contam ainda que eles mesmos em seu primeiro contato com a comunidade, ou com a Renovação Carismática, experimentaram também certo choque e estranhamento devido à enorme distância entre os valores da comunidade e os da sociedade em geral. Para um entrevistado de 25 anos da Toca de Assis, a vida em comunidade era saudável e pura:

É uma convivência saudável, [...] sem mácula, uma convivência - como eu posso dizer pra você - pura, da qual a gente não consegue perceber pela corrupção daquilo que a gente tá vivendo no mundo, né, aquela sedução, a magia do mundo. Então, eu estranhei. Pra mim, todo mundo aqui é gay. Aquela coisa assim, né. Não gostava muito das músicas e não tava entendendo nada do que tava acontecendo.

Essa opção de romper com a sociedade desviando-se de seus valores é claramente assumida pelos jovens com quem tivemos oportunidade de conversar. Essa ruptura é interpretada não como a passagem da vida juve- 
nil/infantil para a idade adulta, mas como a ruptura com uma vida pregressa impregnada de valores mundanos que agora condenam. Em seus depoimentos, os jovens entrevistados referem-se a uma ruptura com uma experiência anterior de vida, descrita como longa. As duas declaraçôes abaixo ilustram esse discurso e também deixam evidente a relatividade da experiência temporal. Os jovens falam como se já houvessem tido uma larga experiência de vida antes do ingresso na comunidade. A primeira é de um membro da comunidade Canção Nova, de 26 anos:

Foi no ano de 1996 que eu resolvi aprofundar mais [...]. Eu tinha por volta de 16, 17 anos. $\mathrm{Na}$ época eu tinha um bom trabalho [...] um excelente trabalho, bom salário, mas percebi que não estava por completo, precisava dar um passo a mais decidindo a minha vocação. [...] quando eu resolvi aprofundar nesse caminho.

A segunda declaração é da mesma jovem cearense já citada, membro da Shalom:

[...] eu conheci a Shalom quando tinha 14 anos. Já faz metade da minha vida que eu conheço a comunidade, que estou no caminho. Mas eu demorei até descobrir que a minha vocação era a Shalom e eu relaxei muito também, fiz muita besteira.

Enquanto os membros das comunidades de vida consideram estar se desviando de um estilo de vida e de valores negativos, a favor do "bem", seus pais muitas vezes percebem essa opção dos filhos de maneira oposta. A reação desses pais assemelha-se à postura dos pais franceses cujos filhos entraram em "seitas". Birman (2000, p. 33) comenta que um desses pais franceses compara as seitas com as drogas. Ambas atraem os jovens, prejudicam suas vidas, embotando sua consciência e tornando-os dependentes. Ambas também seriam sintomas "[...] de uma patologia social mais profunda, que se manifesta sobretudo pela desorientação dos jovens, que não se sentem concernidos pelos valores que seus pais lhes transmitiram".

Essa analogia entre seitas e drogas lembra a aproximação feita por Marx entre religião e ópio. Em ambos os casos, religião e seita seriam culpadas de privar o indivíduo da vontade própria e da capacidade de escolha, como fazem as drogas. Essa analogia sugere também que a religião, como as drogas psicoativas, gera estados modificados de consciência, criando experiências de superação de tensões, relaxando ou dando a sensação de força e poder. Por essas similaridades, religião e droga tanto podem competir pela 
preferência dos adeptos ${ }^{15}$, como podem reforçar-se mutuamente. Esse reforço ocorre, por exemplo, em religiōes que fazem uso ritual de substâncias psicoativas. Atualmente, no Brasil, dois grupos religiosos destacam-se por isso, o Daime e o Rastafari, ambos com um apelo especial entre a juventude (cf., por exemplo, Cunha, 1993).

Para entender a relação entre droga e religião, pode-se adotar o mesmo tipo de argumento que Weber apresenta para entender a relação entre as diferentes esferas da vida e a religião. Como citado antes, Weber (1982b) aponta similaridades que podem gerar ora tensões ora união entre o âmbito religioso e outras esferas. No caso da esfera política, Weber comenta que o sentimento de comunhão gerado pela experiência da guerra e da luta contra um inimigo comum pode competir com, ou reforçar, a comunhão gerada na esfera religiosa. $\mathrm{O}$ mesmo tipo de relação ambígua ocorreria também entre a religião e as esferas eróticas e estéticas. Assim, tanto as artes como o erotismo desempenham papéis similares ao das religiōes, gerando estados modificados de consciência, sentimento de solidariedade e fusão; por isso, as religiôes tanto podem competir com elas como podem reforçá-las, dependendo do contexto no qual cada uma dessas experiências é interpretada e vivida. $\mathrm{O}$ que para esse autor parece estar presente em todas as experiências é a possibilidade de o indivíduo encontrar sentido para sua vida e também sentimentos de transcendência, fusão e pertencimento coletivo. Para usar a linguagem durkheimiana e funcionalista, pode-se dizer que Weber percebia que tais esferas da vida ameaçavam a religião, na medida em que podiam ser funcionalmente religiosas.

Com efeito, a experiência de desvio e ruptura vivenciada pelos jovens que optam pelas comunidades de vida tem apelo e força na medida em que pode gerar um sentimento de forte pertencimento, característico das minorias. Sem dúvida, uma minoria que rompe com a sociedade mais ampla procurando distinguir-se, criando certo sentimento de superioridade, pois possui laços de solidariedade interna extremamente sólidos.

\section{Experiências festivas de efervescência coletiva}

Todas as comunidades analisadas realizam grandes eventos musicais que se assemelham a shows profanos de dança e música. A Canção Nova é a que mais se destaca nesse sentido, pela capacidade de agregar multidôes nos eventos que organiza ${ }^{16}$. Um dos membros dessa comunidade comenta:
15. Segundo Dalgalarrondo et al. (2004) e Sanchez et al. (2004), pesquisas no Brasil e no exterior têm demonstrado que a religião pode moderar o consumo de álcool e de drogas entre adolescentes e jovens.

16. Oliveira (2003) fornece dados e relatos interessantes sobre esse tipo de experiência na Canção Nova. 
17. A construção desse rincão foi concluída em 2004 .
Nós temos um local chamado Rincão do meu Senhor. Esse lugar reúne hoje com tranqüilidade 15 mil pessoas em um encontro, acontecem em média dois encontros por mês. São nos finais de semana e reúnem com tranqüilidade 15 mil pessoas-em eventos grandes chega a 30 mil pessoas. E, atualmente, né, já estamos construindo um rincão ${ }^{17}$ para 60 mil pessoas, porque o atual já não suporta mais, tá se tornando muito pequeno.

A música tem um papel muito forte nas vivências religiosas em geral, como tem sido apontado por muitos autores, inclusive Weber (1982b). Para os jovens, a música parece ser ainda mais importante, fato amplamente reconhecido por qualquer pastoral de juventude. Pesquisas com jovens evangélicos, brasileiros e argentinos, destacam a importância desempenhada pelos grupos e bandas musicais (cf. Seman 1994, Leitão, 1997, entre outros). Há relativamente poucos estudos sobre o desempenho de bandas católicas, mas elas são bem numerosas e estão presentes em várias das comunidades pesquisadas. Além disso, o fervor de certos jovens em eventos religiosos musicais de massa, como os realizados por padres cantores, como o padre Marcelo Rossi e o padre Zeca (“Deus é dez"), tem chamado a atenção da mídia. Esse fervor assemelha-se ao entusiasmo juvenil em shows musicais os mais variados.

Em sua análise sobre a busca do sentimento de proteção e aconchego da comunidade, no mundo contemporâneo, Bauman (2003) refere-se às "comunidades estéticas", que seriam experiências passageiras e de massa, como shows musicais, cultos de fãs às celebridades e ídolos da mídia, entre outras. Atribuindo-lhes um sentido próprio e sagrado, o mundo religioso promove experiências similares e por vezes aparentemente idênticas, que geram também sentimento de segurança e proteção.

Sem dúvida, muitas são as experiências que criam esse tipo de sentimento: o êxtase em grupos religiosos, a dança, a música, o uso de drogas e o sexo, e também guerras, lutas, violência e forte engajamento político, entre outras. Aparentemente distintas, essas experiências assemelham-se por reforçarem o sentimento de coletividade e por sustentarem posiçóes extremas e radicais, independentemente de seu conteúdo. A juventude conhecida pelo lema "sexo, drogas e rock'n roll" poderia estar buscando, dessa forma, o mesmo que os jovens com seu virtuosismo religioso. Propor a possibilidade de uma interpretação funcionalista desse tipo não significa negar interpretações complementares, que levam em conta o conteúdo de cada experiência em si, mas tem o propósito de não deixar que os conteúdos de discursos e práticas tão distintos ofusquem essas dimensões. 
Considerações finais

Para entender a opção dos jovens pelas "comunidades de vida no Espírito Santo", procuramos refletir neste artigo sobre o conceito de juventude e subjetividade juvenil no mundo contemporâneo. Sem ambição de discutir todas as dimensões ou toda a literatura sobre esse tema, defendemos a idéia de que se pode falar de uma subjetividade juvenil, apesar de toda a pluralidade que a categoria jovem assume em um contexto social marcado por uma diversidade extrema.

A partir dessa idéia, sugerimos que os discursos de jovens que pertencem às "comunidades de vida no Espírito Santo", suas alegadas motivações, os sentimentos e as experiências de vida que descrevem, expressariam essa suposta subjetividade juvenil contemporânea. Argumentamos também que essa subjetividade não é necessariamente religiosa em termos de conteúdo, podendo manifestar-se, pelo contrário, em uma forte anti-religiosidade. No entanto, o que a caracteriza é ser funcionalmente religiosa. Os próprios movimentos juvenis de luta por liberdade individual estariam alimentados por experiências grupais de origem coletiva que seriam alimentadas por fortes vínculos de solidariedade internos ao movimento.

A subjetividade juvenil teria assim uma afinidade eletiva com experiências coletivistas e comunitárias, entendidas por Durkheim (1985) como funcionalmente "religiosas". Devido a esse tipo de afinidade, os jovens seriam os mais aptos a tomar atitudes de heroísmo extremo, a ser revolucionários ou virtuoses religiosos, ou a se engajar em violência radical, optando por vezes pelo que Durkheim (1977) chamou de "suicídio altruísta"18.

Da mesma forma, a música teria muito valor e importância para a juventude contemporânea por oferecer experiências de transcendência e comunhão. A afinidade entre uma subjetividade, ou subcultura, juvenil e experiências coletivistas seria, assim, perceptível nos recorrentes fenômenos de "efervescências coletivas" juvenis (tais como manifestações musicais, orgiásticas ou com alucinógenos) e ainda nas manifestaçôes de violência geradoras também do sentimento de coletividade.

18. Aqui não se pode deixar de mencionar a juventude dos chamados "homens-bombas", ligados aos movimentos islâmicos radicais. A luta armada no Brasil também foi vivida e liderada por jovens. 


\section{Referências Bibliográficas}

Ariès, Philippe. (1981), História social da criança e da família. São Paulo, LTC.

BAUMAN, Zygmunt. (2003), Comunidade: a busca por segurança no mundo atual. Rio de Janeiro, Jorge Zahar.

Berger, Peter L. (1985), O dossel sagrado. São Paulo, Paulus.

Birman, P. (2000), Religiosidade, pluralismo e nação: as seitas na França hoje. Tese para Concurso Público de Professor Titular da Universidade do Estado do Rio de Janeiro.

Campiche, Roland. (1997), Cultures jeunes et religions en Europe. Paris, Les Éditions du Cerf.

CamurÇA, Marcelo A. (2001), "Religiosidade moderna e esclarecida entre os universitários de Juiz de Fora - MG”. Debates do NER, 2 (2): 37- 65.

Cardoso, Alexandre, Perez, Lea \& Oliveira, Luciana. (2001), “Quem mora ao lado? O pecado ou a virtude? Um estudo comparativo sobre religião e política entre estudantes de Ciências Sociais e de Comunicação da FAFICH - UFMG”. Debates do NER, 2 (2): 65-102.

CARranza, Brenda. (2000), Renovação Carismática: origens mudanças e tendências. Aparecida, Editora Santuário.

CoHEn, Martine. (1990), “Les renoveaux catholique et juif en France”. In: CHAMPION, F. \& Hervieu-Leger, D. De l'émotion en religion; renouveaux et traditions. Paris, Centurion, pp. 123-169.

(1997), "La regulation catholique des pratiques pentecôtistes au sein du Renouveau Charismatique Français”. In: Bertin, George \& Rousseau, Marie Claude, Pentêcote: de l'intime au social. Nantes, Siloë - Université Catholique de l'Ouest, pp.131-150

CSORDAS, Thomas. (1997), Language, charisma and creativity: the ritual life of a religious movement. Berkeley, University of California Press.

CunHa, Olívia Gomes da. (1993), “'Fazendo a coisa certa’: reggae, rastas e pentecostais em Salvador”. Revista Brasileira de Ciências Sociais, 8 (23): 120-137.

Dalgalarrondo, Paulo et al. (2004), "Religião e uso de drogas por adolescentes". Revista Brasileira de Psiquiatria, 26 (2): 82-90.

Durkheim, E. (1977), O suicídio. 2 ed. Lisboa, Editorial Presença. (1985), As formas elementares da vida religiosa. São Paulo, Paulinas.

Evans-Pritchard, E. (2002), Os nuer. São Paulo, Perspectiva.

FERnANDes, Sílvia R. A. (2002), "Prática religiosa e participação social”. In: Ceris (2002), Desafios do catolicismo na cidade: pesquisa em regiōes metropolitanas brasileiras. São Paulo, Paulus, pp. 88-136.

270 Tempo Social, revista de sociologia da USP, v. 17, n. 2 
(2004), "Ser padre pra ser santo"; "Ser freira pra servir": a construção social da vocação religiosa - uma análise comparativa entre rapazes e moças no Rio de Janeiro. Tese de doutorado em Ciências Sociais, Universidade do Estado do Rio de Janeiro. Ferreira, Walace. (2005), "Pão da Vida: uma alternativa religiosa à sociedade contemporânea”. Resumo publicado nos anais do XII Congresso Brasileiro de Sociologia, p. 476.

Fulton, John. (2003), Religion youth and young adults. Trabalho apresentado na XXVII Conferência SISR/ISSR, Turim, jul. 2003.

LeITÃo, Márcia. (1997), Igreja Universal: a guardiā da juventude. Dissertação de mestrado, Rio de Janeiro, Programa de Pós-Graduação em Ciências Sociais da Universidade do Estado do Rio de Janeiro.

Lopes, Paulo Victor Leite. (2005), “O 'carisma' como um dom: vocação e reciprocidade em comunidades de Aliança e Vida no Espírito Santo”. Resumo publicado nos anais XII Congresso Brasileiro de Sociologia, p. 444.

Machado, Maria das Dores C. (1996), Carismáticos e pentecostais: adesão religiosa na esfera familiar. São Paulo/Campinas, Anpocs/Editores Autores Associados.

Mariz, Cecília L. (2001), "Pentecostalismo, Renovação Carismática e Comunidade de Base: uma análise comparada”. Cadernos do Ceris, 1 (2): 11-42 e 69-73.

. (2003), “A Renovação Carismática Católica: uma igreja dentro da Igreja?”. Civitas, 3 (1): 169-186, Porto Alegre, PUC-RS.

(2005), "Comunidades de Vida no Espírito Santo: um novo modelo de família?". In: Duarte, Luis Fernando et al. (org.). Família e religião. Rio de Janeiro, Contra Capa.

MEAD, Margareth. (1995), Adolescencia y cultura en Samoa. Barcelona, Paidós.

Minuzzi, Débora. (2005), “Comunidade de Vida na MRCC”. Resumo publicado nos anais XII Congresso Brasileiro de Sociologia, p. 361.

Miranda, Júlia. (1999), Carisma, sociedade e política: novas linguagens do religioso no político. Rio de Janeiro, Jorge Zahar.

Novaes, Regina. (2004), "Os jovens sem religião: ventos secularizantes, espírito da época e novos sincretismos”. Estudos Avançados, 18 (52): 321-330, set./dez.

Oliveira, Eliane Martins. (2003), "O mergulho no Espírito de Deus": diálogos (im)possiveis entre a Renovação Carismática Católica (RCC) e a Nova Era na Comunidade de Vida no Espírito Canção Nova. Dissertação de mestrado, Rio de Janeiro, Programa de Pós-Graduação em Ciências Sociais da Universidade do Estado do Rio de Janeiro.

. (2004), "O mergulho no Espírito Santo: interfaces entre o catolicismo carismático e a Nova Era (o caso da comunidade de vida no Espírito Santo Canção Nova)". Religião e Sociedade, 24 (1): 85-112. 
Peralva, Angelina. (1996), A juvenização da violência e angústia da morte. Anpocs, Caxambu.

SANCheZ, Z. et al. (2004), "Fatores protetores de adolescentes contra o uso de drogas com ênfase na religiosidade". Ciência \& Saúde Coletiva, 9 (1): 43-55.

Seman, Pablo F. (1994), "Identidad de los jóvenes pentecotales”. In: Frigerio, Alejandro (org.). El pentecostalismo en la Argentina. Buenos Aires, Centro Editor de América Latina, pp. 80-94.

Serrano, Barbara. (2003), "Le 'groupe jeune', entre individualisme et soumission à l'autorité”. In: Corten, André, Dozon, J.-P. \& Oro, Ari Pedro (orgs.). Les nouveaux conquerants de la foi: la Eglise Universalle du Royaume de Dieu. Paris, Karthala, pp. 57-65.

Sposito, Marília Pontes A. (2001), "Produção do conhecimento sobre juventude na área de educação no Brasil a educação". International Studies on Law and Education. São Paulo, 4: 37-55.

Steil, Carlos Alberto, Alves, Daniel \& Herrera, Sônia. (2001), "Religião e política entre os alunos de Ciências Sociais: um perfil". Debates do NER, 2 (2): 9-36.

URQHART, Gordon. (2002), A armada do papa: os segredos e o poder das novas seitas da Igreja Católica. Rio de Janeiro, Record.

Weber, Max. (1982a), “A ciência como vocação”. In: Ensaios de sociologia. Rio de Janeiro, Zahar.

(1982b), "Rejeiçôes religiosas do mundo e suas direçôes". In: Ensaios de sociologia. Rio de Janeiro, Zahar.

(1991), Economia e sociedade. Brasília, Editora da UnB.

ZANETTI, Hermes. (1999), Juventude e revolução: uma investigação sobre atitude revolucionária no Brasil. Dissertação de mestrado, Brasília, Instituto de Ciência Política da Universidade de Brasília.

\section{Resumo}

Comunidades de vida no Espírito Santo: juventude e religião

Dados coletados sobre a Renovação Carismática Católica (RCC) têm revelado a importância dos jovens na criação, na manutenção e no crescimento das chamadas "Comunidades de Vida no Espírito". A maior parte dessas comunidades foi criada para el ou por jovens. Dentre as estudadas, a Toca de Assis é a que mais chama a atenção pela juventude de seus membros, sendo também a que opta por um estilo mais radical de vida na busca da santidade. A partir desses dados e da reflexão sobre o conceito de juventude na modernidade, pretende-se neste artigo refletir sobre a radicalidade das experiências juvenis em distintas esferas da vida, mas especialmente na religião e na 
política, para entender o papel tenso e ambíguo desempenhado pelos jovens em movimentos religiosos diversos.

Palavras-chave: Juventude; Religiāo; Comunidade; Catolicismo; Movimento carismático.

\section{Abstract}

Communities of life in the Holy Spirit: youth and religion

Data collected on the Catholic Charismatic Renovation (CCR) has shown how important youths are in the creation, maintenance and growth of the so-called "Communities of Life in Spirit". The majority of these communities were either founded for or by young people. Among those studied, "Toca de Assis" is the one that stands out because of the age of its members, and because it also chooses a more radical life style in the search for spiritual enlightenment. Based on these data and on the discussion of the concept of youth in modernity, this paper aims to treat the radicalism of juvenile experiences in different domains of life, especially with regard to religion and politics, in order to understand the tense and ambiguous role taken on by youngsters in different religious movements.

Keywords: Youth; Religion; Community; Catholicism; Charismatic movement.

Texto recebido e aprovado em $7 / 10 / 2005$.

Cecilia Loreto Mariz é professora de Sociologia no Departamento de Ciências Sociais da UERJ e desenvolve pesquisa sobre o pentecostalismo e o catolicismo no Brasil. E-mail:cemariz@alternex. com.br. 